\title{
Comparative evaluation of Bethesda system with conventional reporting method in assessment of thyroid malignancy rate
}

\author{
Srivastava M.K. ${ }^{1}$, Srivastava K. ${ }^{2}$, Baig M.Q. ${ }^{3}$, Asharam $^{4}$, Vahikar S. ${ }^{5}$ \\ ${ }^{1}$ Dr. Manglesh Kumar Srivastava, Associate Professor, Department of Pathology, GMC, Ajamgarh, ${ }^{2}$ Dr. Kanchan \\ Srivastava, Associate Professor, Department of Pathology, BRD Medical College Gorakhpur, ${ }^{3}$ Dr. M.Q. Baig, Associate \\ Professor, Department of Radiation Oncology, BRD Medical College Gorakhpur, ${ }^{4}$ Dr. Asharam, Resident, Department \\ of Pathology, BRD Medical College Gorakhpur, ${ }^{5}$ Dr. Shilpa Vahikar, Associate Professor, Department of Pathology, \\ BRD Medical College Gorakhpur, UP, India.
}

Corresponding Author: Dr. Kanchan Srivastava, Associate Professor, Department of Pathology, BRD Medical College, Gorakhpur, UP, India. E-mail Id: mall. shilpa@yahoo.co.in

\begin{abstract}
Introduction: Fine needle aspiration cytology (FNAC) of thyroid is non-invasive, cost-effective \& extremely useful technique in identifying a substantial proportion of thyroid nodules as benign \& appropriately triages patients with thyroid cancer to appropriate surgery. The Bethesda system for reporting thyroid cytology represents a major step towards improved clinical significance, reproducibility, standardization \& greater predictive value of FNAC thyroid. Objective: To categories thyroid lesions according to Bethesda system \& to determine the rate of malignancy in each cytologic category by correlating the result with histopathologic diagnosis on the resected specimens. Material \& Methods: The present study was carried out on 100 patients of thyroid swelling referred to the department of pathology, for FNAC. The reporting was done by using Bethesda system of thyroid cytopathology in comparison to the conventional reporting system. The malignancy rate based on final histopathologic evaluation was analyzed for each of the cytologic groups. Results: Rates of malignancy in each category of conventional system reported on follow up HPE were $16.66 \%$ in non-diagnostic group, $2.17 \%$ in colloid garter, nil in colloid cyst, $25 \%$ in thyroiditis, $7.69 \%$ in follicular lesion/ neoplasm, $33.33 \%$ in indeterminate group, $75 \%$ in suspicious for malignancy \& $100 \%$ in malignant category. Rates of malignancy in each category of Bethesda system on follow up HPE were $16.66 \%$ in Non Diagnostic, $1.58 \%$ in benign category, $28.57 \%$ in atypical of undermined significance, $18.18 \%$ in suspicious for follicular neoplasm, $80 \%$ in suspicious for malignancy \& $100 \%$ in malignant category. Conclusion: By adapting the Bethesda cyto-pathology reporting system malignancy risk in the categories of AFLUS, SM \& Malignant category help to determine a better patient outcome due to proper clinical management.
\end{abstract}

Keywords: Fine needle aspiration, Bethesda system, Thyroid, HPE

\section{Introduction}

Fine needle aspiration cytology (FNAC) is a well established, non-invasive, efficient specific technique for pre-operative investigation of thyroid nodules [1].

Indeterminate results, like suspicious for malignancy \& follicular neoplasm or lesion variability in reporting system \& inadequate specimens limit the utility of FNAC \& may complicate the management of thyroid nodules [2]. Reporting of thyroid FNAC using a standard terminology is not yet widely implemented. Diagnostic terminology varies form institution to another, how ever using a standardized nomenclature

Manuscript received: $5^{\text {th }}$ December 2018

Reviewed: $15^{\text {th }}$ December 2018

Author Corrected: $24^{\text {th }}$ December 2018

Accepted for Publication: 27 $7^{\text {th }}$ December 2018 for reporting thyroid FNA cytology can enhance the communication \& understanding between pathologist \& clinicians. This confusion in diagnostic terminology \& clinician perception of its inconsistency was addressed in 2007 by the National cancer Institute \& forms the framework of the Bethesda system for reporting thyroid cytopathology (TBSRTC) [3]. The purpose of this study is to categorize thyroid lesions by FNAC using the classification of Bethesda system including nondiagnostic, benign, atypical follicular lesion of undetermined significance (AFLUS), follicular/hurtle cell neoplasm, suspicious of malignancy \& malignant categories \& to determine the rate of malignancy in each cytologic category by correlating the results with histopathologic diagnosis on the reseated specimens. 


\section{Materials \& Methods}

This is a prospective study of 100 cases of FNAC's of thyroid lesions performed, reviewed \& categorized using conventional \& Bethesda system of reporting. The study was performed at BRD Medical College, Dept. of pathology during July 2015 to June 2016. Thyroid FNAC slides were stained using HPE \& Papanicolaou stains.

Study Site: This study was conducted in the Department of pathology, B.R.D Medical College, Gorakhpur, U.P, Duration of Study was 12 months form July 2015 to June 2016.

Study Design: Observational study

Case Selection: The study was carried out on patients with palpable thyroid swelling presenting in the END OPD at Nehru Chiketsalaya, B.R.D. Medical College, Gorakhpur and were sent to Department of pathology for FNAC.

\section{Inclusion Criteria}

All patients presenting to pathology department for FNAC of thyroid swelling in any lobe of thyroid selected by clinical palpation.

\section{Exclusion Criteria}

1. Patient not giving consent for FNAC

2. Patient for whom Autolysed/Inadequate tissue sample were received.

Sample Size: Study was conducted on the 100 case of thyroid swelling.

Method of Study: All Patients presenting with thyroid nodule and fulfilling the inclusion criteria were included in the study. All relevant data Demographic details, Clinical Details, Routine investigation and serum $T_{3}, T_{4}$ and TSH level was reworded for each patient.

After taking informed consent from the patient, FNAC of thyroid swelling was done under all aseptic precautions smears were stained by $\mathrm{H}$ and $\mathrm{E}$ and Papanicolaou methods.

Each cytology slide was reported by using two methods of reporting

a. The Conventional system.

b. The Bethesda system.

The cytology slides were reporting by using two systems conventional \& Bethesda. According to
Conventional system of reporting, cytological diagnosis was categorized into following 7 groups [4,5].

Non Diagnostic or unsatisfactory: When smears are hemorrhagic or containing less than 6 groups of wellpreserved follicular cells on each of at least two slides.

Colloid goiter:- When smears contained follicular cells with abundant thick colloid in the background.

Colloid cysts:- When follicular cells, thin or thick colloid in the background and hemosiderin laden macrophages were seen in the smears.

Follicular lesions/Neoplasm:- When smears contain many follicular cells without or scanty colloid in the background or when smears contain predominant population of Hurthle cells, the differential diagnosis would include hyperplastic adenomatoid nodule with Hurthle cell change, Hurthle cell adenoma, and Hurthle cell carcinoma.

Indeterminate smears:- When smears containing cells with findings that were not clearly benign but were not diagnostic of a neoplasm or malignant lesions.

Suspicious for malignancy:- Suspicious when aspirates suggest a follicular neoplasm, ie., hypercellular sample with scant colloid and a significant proportion of microfollicules, trabeculae, or crowded overlapping clusters of follicular cells (also includes lesions consisting of oncocytic [Hurthle cell] neoplasms).

\section{Malignant lesions}
a) Papillary Carcinoma
b) Medullary Carcinoma
c) Anaplastic Carcinoma
d) Lymphoma
e) Metastatic Carcinoma

According to the Bethesda system of reporting, cytological diagnosis was categorized into following 6 categories [6].

Non Diagnostic or unsatisfactory: Cyst fluid only virtually a cellular specimen other (obscuring blood, clotting artifact, etc).

Benign:- Consistent with a benign follicular nodule (includes adenomatoid nodule, colloid nodule, etc) Consistent with lymphocytic (Hashimoto) thyroiditis in the proper clinical context. Consistent with granulomatous (sub acute) thyroiditis others. 


\section{Original Research Article}

Atypia of Undetermined significance (AUS) or atypical follicular lesion of undetermined significance (FLUS)- As per the guidelines of the Bethesda system, aspirates which were considered adequate, had some features of atypia but could not be categorized definitely into either of the benign, SFN, SM, or Malignancy categories were grouped under this category.

Follicular neoplasm or Suspicious for a follicular neoplasm:- Aspirates with cytomorphologic features of moderate to high cellularity, scant or absent colloid, with predominantly microfollicular or trabecular configuration of follicular cells were grouped under this category. Specify if Hurthle cell (oncocytic) type.
Suspicious for malignancy: Suspicious for papillary carcinoma, Suspicious. For medullar carcinoma, Suspicious for metastatic carcinoma, Suspicious for lymphoma

Malignant: Papillary Thyroid carcinoma, poorly differentiated carcinoma, Medullar thyroid carcinoma, undifferentiated (anaplastic).

As per Guidelines of Bethesda System, Category 3 cases were subjected to repeat FNAC. We compared FNA diagnoses of these 100 cases with the diagnoses obtained on HPE \& calculated the malignancy risk for each category.

\section{Results:}

The final corresponding histopathologic diagnosis was then compared. Cases of FNAC with no corresponding histopathology were excluded. Only cases with pre-operative FNA cytology \& post- operative histology available were included in the study.

Table-1: Comparison of pre-operative FNAC diagnosis with the diagnosis on HPE after surgical resection \& calculation of malignancy risk for each category of conventional method of reporting-

\begin{tabular}{|l|c|c|c|c|c|}
\hline Lesions (Of FNA Reporting) & No & \multicolumn{2}{|c|}{ Histopathology } & Total & Malignancy Risk \% \\
\hline & & Benign & Malignant & & \\
\hline Non-diagnostic or Unsatisfactory & 06 & 05 & 01 & 06 & $16.66 \%$ \\
\hline Colloid goiter & 46 & 45 & 01 & 46 & $2.17 \%$ \\
\hline Colloid Cyst & 09 & 09 & 00 & 09 & $00 \%$ \\
\hline Thyroiditis & 08 & 06 & 02 & 08 & $25 \%$ \\
\hline Follicular lesions/Neoplasm & 13 & 12 & 01 & 13 & $7.69 \%$ \\
\hline Indeterminate & 06 & 04 & 02 & 06 & $33.33 \%$ \\
\hline Suspicious for malignancy & 04 & 01 & 03 & 04 & $75 \%$ \\
\hline Malignant & 08 & 00 & 08 & 08 & $100 \%$ \\
\hline Total & $\mathbf{1 0 0}$ & $\mathbf{8 2}$ & $\mathbf{1 8}$ & $\mathbf{1 0 0}$ & $\mathbf{1 0 0 \%}$ \\
\hline
\end{tabular}

Accordingly, out of 6 cases of non-diagnostic category 1 case was found to be malignant. So the malignancy risk in this study was $1 \%$. In Colloid goitre, Malignancy risk was found to be $2.17 \%$, in colloid cyst- $0 \%$, in the thyroiditis $25 \%$, $7.69 \%$ in the Follicular lesions/neoplasia \& 33.33\% in indeterminate category. Out of 4 cases of Suspicious for malignancy, 3 cases were found to be malignant on HPE, So the malignancy risk in this category was $75 \%$ \& in malignant category it was $100 \%$.

Table- 2: Comparison of pre-operative FNAC diagnosis with the diagnosis on HPE after surgical resection \& calculation of malignancy risk for each category of Bethesda system of reporting-

\begin{tabular}{|c|c|c|c|c|c|}
\hline \multirow[t]{2}{*}{ Lesions (Of FNA Reporting) } & \multirow[t]{2}{*}{ No } & \multicolumn{2}{|c|}{ Histopathology } & \multirow[t]{2}{*}{ Total } & \multirow{2}{*}{$\begin{array}{c}\text { Malignancy } \\
\text { Risk \% }\end{array}$} \\
\hline & & Benign & Malignant & & \\
\hline Non-diagnostic or Unsatisfactory & 06 & 05 & 01 & 06 & $16.66 \%$ \\
\hline Benign & 63 & 62 & 01 & 63 & $1.58 \%$ \\
\hline $\begin{array}{l}\text { Atypia of Undetermined significance or } \\
\text { follicular lesion of Undetermined significance }\end{array}$ & 07 & 05 & 02 & 07 & $28.57 \%$ \\
\hline $\begin{array}{l}\text { Follicular neoplasm or Suspicious for } \\
\text { follicular neoplasm }\end{array}$ & 11 & 09 & 02 & 11 & $18.18 \%$ \\
\hline Suspicious for malignancy & 05 & 01 & 04 & 05 & $80 \%$ \\
\hline Malignant & 08 & 00 & 08 & 08 & $100 \%$ \\
\hline Total & 100 & 82 & 18 & 100 & $100 \%$ \\
\hline
\end{tabular}




\section{Original Research Article}

Out of 6 cases of non-diagnostic category 1 found to be malignant on HPE. So the malignancy risk in this category was $16.16 \%$.

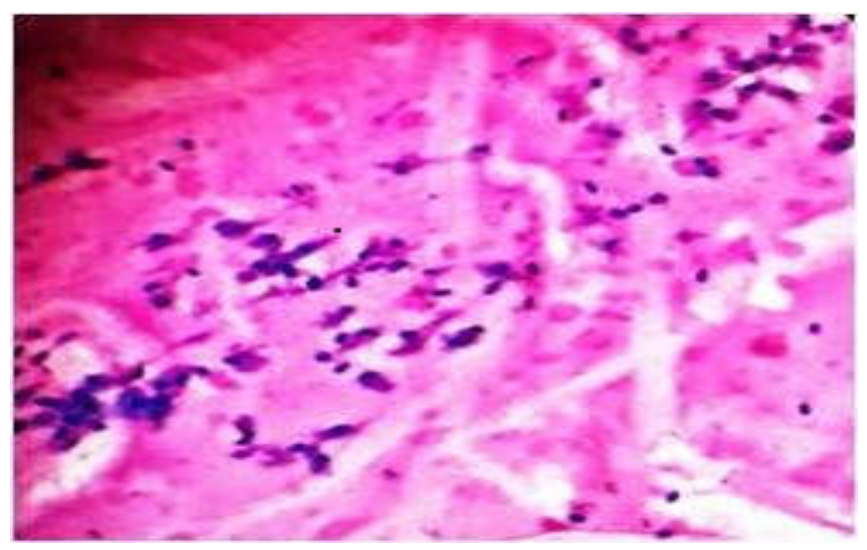

Microphotograph (1)

H \&E stained smear of FNAC of Colloid goiter.

Benign follicular epithelial cells in abundant colloid background (400X).

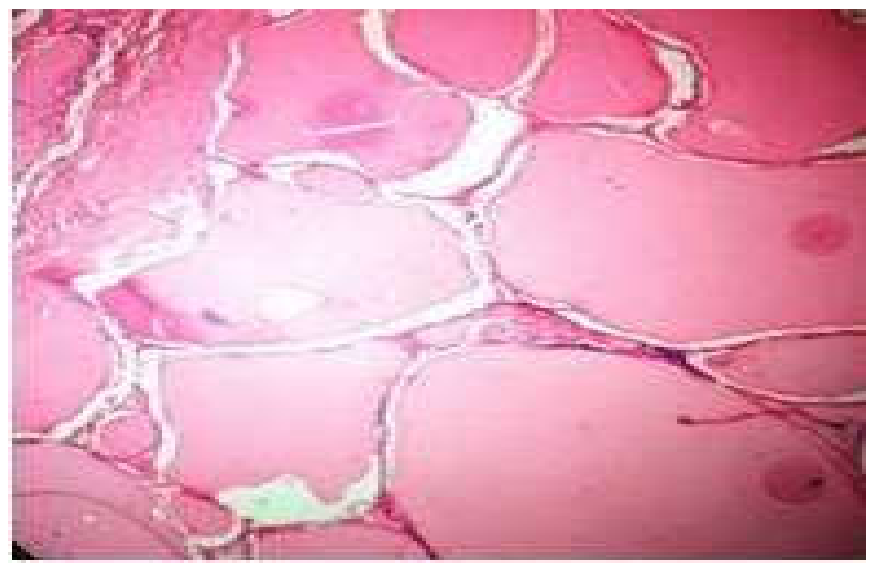

Microphotograph (2)

H\&E stained section of colloid goiter showing huge follicles lined by flattend epithelium filled with abundant colloid material.(400X)

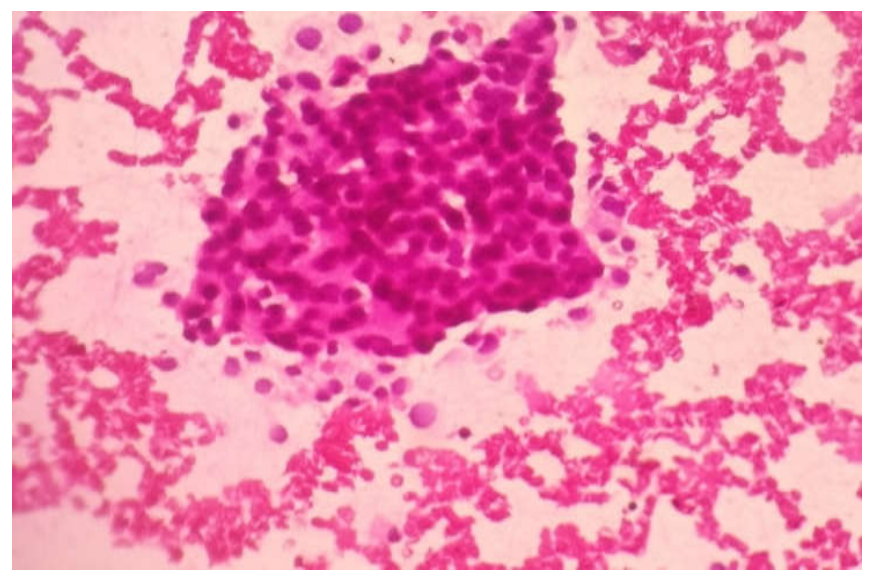

Microphotograph (3)

H\&E Smear of FNAC of follicular neoplasm showing, microfollicular pattern in bloody colloid free background (400X). 


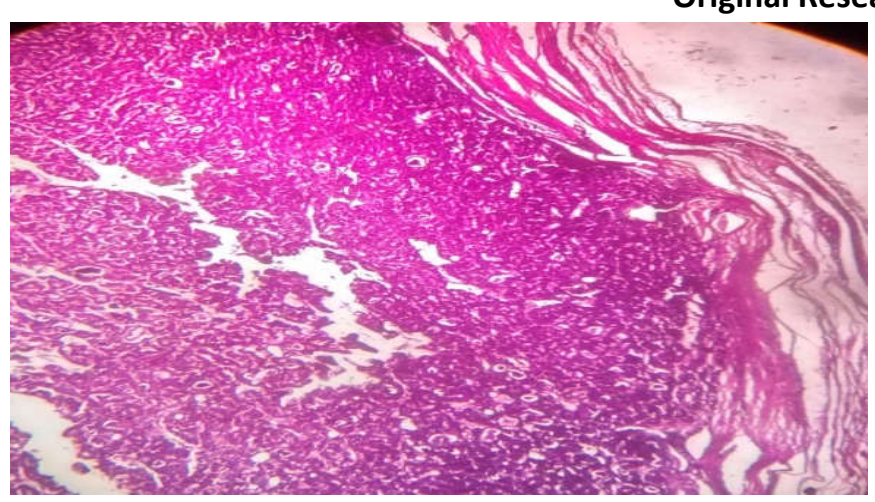

Microphotograph (4)

H\&E section of follicular adenoma showing microfollicular pattern of growth with intact fibrous capsule (100X)

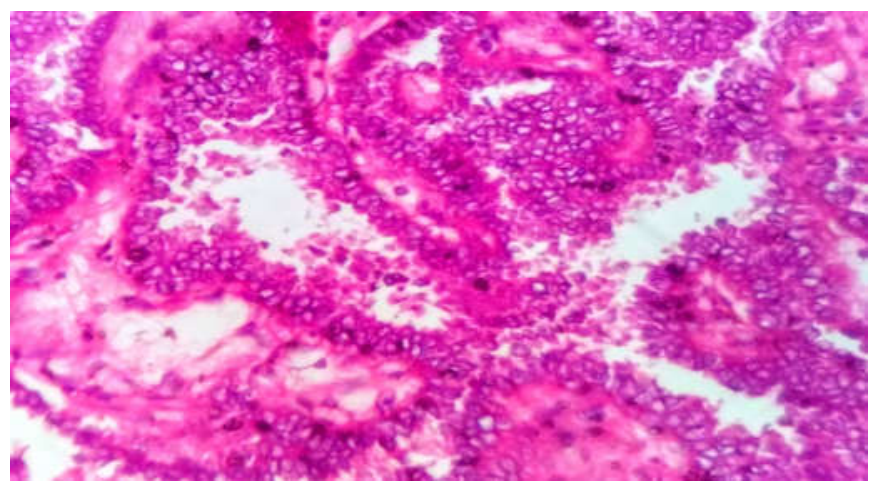

Microphotograph (5)

H\&E stained section of papillary carcinoma showing optically clear nucleus and nuclear pseudoinclusion, with desmoplastic reaction (400x)

In Benign category, 1 found to be malignant on HPE, so the malignancy risk came to be $1.58 \%$. 7 out of 2 surgically resected cases of AFLUS were found to be malignant by HPE in the follow-up period, giving a malignancy risk of $28.57 \%$ in this category. About 11 out of 2 cases of Follicular neoplasm/suspicious for follicular neoplasm were found to be malignant on HPE giving a malignancy risk of $18.18 \%$. In 5 cases of Suspicious for malignancy, 4 turned out to be malignant by HPE in the follow-up, So the malignancy risk was $80 \%$ in this category. Out of 8 Case in the malignant category, all turned out to be malignant, giving a malignancy risk of $100 \%$ in this category.

\section{Discussion}

FNAC of the thyroid is the key pre-operative investigation of thyroid lesions. It is critical that pathologist communicate thyroid FNAC diagnosis to the physicians in terms that are concise, helpful \& unambiguous, Historically, terminology for thyroid FNA has varied significantly form one laboratory to another, creating confusion in some cases when reported by conventional method of thyroid reporting.

To address terminology \& other issues related to thyroid FNAC, the 'National Cancer Institute' hosted the 'NCI thyroid FNA state of the science conference' in Bethesda in 2007 [7].

The discussions \& conclusions regarding terminology \& morphologic criteria form the NCI meeting, Summarized in the publications by Baloch et al [8].

The Bethesda system for reporting thyroid cytopathology recommends 6 general diagnostic categories. Each of the categories has an implied cancer risk ranging form $0 \%$ to $3 \%$ for the benign category to virtually $100 \%$ for the malignant category that links it to a rational clinical management guideline [7]. 


\section{Original Research Article}

Table-3: The Bethesda System for reporting Thyroid Cytopathology

Implied Risk of Malignancy and recommended clinical management.

\begin{tabular}{|l|c|c|}
\hline Diagnostic Category & Risk of Malignancy (\%) & Usual Management \\
\hline Nondiagnostic or Unsatisfactory & $1-4$ & $\begin{array}{c}\text { Repeat FNA with ultrasound } \\
\text { guidance }\end{array}$ \\
\hline Benign & $0-3$ & clinical follow-up \\
\hline $\begin{array}{l}\text { Atypia of undetermined Significance or } \\
\text { Follicular lesion of Undetermined Significance }\end{array}$ & $\sim 5-15^{+}$ \\
\hline $\begin{array}{l}\text { Follicular Neoplasm or Suspicious for a } \\
\text { Follicular Neoplasm }\end{array}$ & $15-30$ & Surgical lobectomy \\
\hline $\begin{array}{l}\text { Suspicious for Malignancy } \\
\text { Malignant }\end{array}$ & $60-75$ & $\begin{array}{c}\text { Near-total Thyroidectomy or } \\
\text { surgical lobectomy }\end{array}$ \\
\hline
\end{tabular}

We used conventional method of reporting hence before \& we tried to improve our reporting technique because the clinicians had difficulty in understanding the complexities of our thyroid cytology reporting. While reviewing the FNACs in our study, it was noted that many of the descriptions \& diagnoses that were offered previously seemed like a vague \& complicated jargon of pathological terminologies, which would be of no clinical significance to the clinicians.

However when we reported the cases as per the standardized nomenclature of the Bethesda system, it seemed more Systematic \& with great clarity.

We compared our studies with the studies done by Jo et al, Yassa et al, Yang et al, Nayar\& Ivanovic et al \& Santosh Kumar Mondal et al. Comparison of the percentages of Malignancy risk of present study with other studies.

Table-4: Comparison with other studies.

\begin{tabular}{|c|c|c|c|c|c|}
\hline Diagnostic Category & Present Study & $\begin{array}{c}\text { Santosh Kumar } \\
\text { Mondal et al [5] }\end{array}$ & $\begin{array}{c}\text { Yassa et al } \\
\text { [9] }\end{array}$ & $\begin{array}{c}\text { Yang et } \\
\text { al [10] }\end{array}$ & $\begin{array}{c}\text { Nayar \& Ivanovic } \\
\text { et al [11] }\end{array}$ \\
\hline Non-diagnostic & $16.66 \%$ & $0 \%$ & $10 \%$ & $10.7 \%$ & $9 \%$ \\
\hline Benign & $1.58 \%$ & $4.5 \%$ & $0.3 \%$ & $0.7 \%$ & $2 \%$ \\
\hline AFLUS & $28.57 \%$ & $20 \%$ & $24 \%$ & $19.2 \%$ & $6 \%$ \\
\hline SFN & $18.18 \%$ & $30.6 \%$ & $28 \%$ & $32.2 \%$ & $14 \%$ \\
\hline SM & $80 \%$ & $75 \%$ & $60 \%$ & $64.8 \%$ & $53 \%$ \\
\hline Malignant & $100 \%$ & $97.8 \%$ & $97 \%$ & $98.4 \%$ & $97 \%$ \\
\hline
\end{tabular}

The Malignancy risk for the different categories in our study has corroborated well with the implied risk mentioned in the Bethesda system \& also with studies of Santosh Mondal et al, Yassa et al, Yang et al \& Nayar \& Invanovic et al though few differences have been noted.

The rate of Malignancy in the non-diagnostic group in our study was $16.66 \%$. This was higher than that reported in other series $[5,9,10,11]$.

That could be because of inadequacy which is am inherent limitation in diagnostic cytopathology especially for cystic lesions but it can be minimized by targeted FNAC under USG guidance.

The rate of Malignancy in AFLUS \& Follicular Neoplasm was $28.57 \%$ \& $18.18 \%$ in present study respectively. These two categories are Heterogeneous, and their diagnostic criteria are subjective to inter \& intra-observer variability. This can explain the wide range of rate in other studies.

The rate of Malignancy in Suspicious category was $80 \%$ \& in malignant category was $100 \%$ in our study. Which was comparable with the studies done by Santosh Mondal et al, Yassa et al \& Yang et al $[5,9,10]$. 
Original Research Article

\section{Conclusion}

This study is a prospective analysis of reporting of thyroid aspiration smears by TBSRTC which can enhance the communication between pathologists \& clinicians \& approach for patient's management. The high Malignancy risk in AFLUS, SM \& Malignant categories reflects the importance of these categories in the Bethesda system of reporting to determine a better patient outcome due to proper clinical management of thyroid swellings.

Advantage: In comparison to the conventional system Bethesda system categories the various thyroid lesions as benign, atypical, suspicious and malignant cases. This categorization of patients in accordance with their severity confers the advantage of better communication with clinicians followed by appropriate triage \& treatment to ensure favorable outcome for patients.

\section{Contribution by different authors}

Data Collection: Dr. Baig, Dr. Shilpa, Dr. Asharam. Procedure: Dr. Shilpa, Dr. Kanchan. Dr. Asharam, Writing of Manuscript: Dr. Shilpa, Dr. Kanchan, Interpretation: Dr. Manglesh, Dr. Shilpa, Dr. Kanchan Critical Review: Dr. Manglesh, Dr. Baig.

Findings: Nil; Conflict of Interest: None initiated Permission from IRB: Yes

\section{References}

1. Bukhari MH, Sindi KA, Niazis, Arshad M, Akhtar ZM (2012) Better Thyroid cytopathology Reporting System may increase the clinical management \& patients outcome: with Review of Literature. J. Cyto/ Histo /3: 158. Doi:10.4172/2157-7099.1000158

2. Moslavac S, Matesa N, Kusić Z. Thyroid fine needle aspiration cytology in children and adolescents. Coll Antropol. 2010 Mar;34(1):197-200.

3. Shagufta Tahir Mufti, Rihab Monh. The Bethesda system for reporting thyroid cytopathology A five years retrospective review of one center experience. Int. J. health Sci (Qassim), 2012 June; 6(2) : 159-173.
4. Bukhari MH, Niazi S, Hanif G, et al. An updated audit of fine needle aspiration cytology procedure of solitary thyroid nodule. Diagn Cytopathol. 2008 Feb;36 (2): 104-12. doi: 10.1002/dc.20731.

5. Santosh Kumar Mondal, Simant Sinha, Bijan Basak, Dipanwita Nag Roy \& Swapan Kumar Sinha. The Bethesda System for reporting thyroid fine needle aspirates. Journal of cytology, Vol.30,No.2,April-June 2013,94-99. Doi:10.4103/0970-9371.112650

6. Langer JE, Baloch ZW, McGrath C, et al. Thyroid nodule fine-needle aspiration. Semin Ultrasound CT MR. 2012 Apr;33(2):158-65. doi: 10.1053/j.sult.2011. 12.002 .

7. Edmund S. Cibas,MD, and Syed Z Ali, MD. The Bethesda system for reporting thyroid cytopathology AM.J.Clipathol 2009;132:658-665

8. Baloch ZW, Cibas ES, Clark DP, et al. The National Cancer Institute Thyroid fine needle aspiration state of the science conference: a summation. Cytojournal. 2008 Apr 7;5:6. doi: 10.1186/1742-6413-5-6.

9. Yassa L, Cibas ES, Benson CB, Frates MC, et al. Long-term assessment of a multidisciplinary approach to thyroid nodule diagnostic evaluation. Cancer. 2007 Dec 25;111(6):508-16.

10. Yang J, Schnadig V, Logrono R, et al. Fine-needle aspiration of thyroid nodules: a study of 4703 patients with histologic and clinical correlations. Cancer. 2007 Oct 25;111(5):306-15.

11. Nayar R, Ivanovic M. The indeterminate thyroid fine-needle aspiration: experience from an academic center using terminology similar to that proposed in the 2007 National Cancer Institute Thyroid Fine Needle Aspiration State of the Science Conference. Cancer. 2009 Jun 25; 117 (3): 195-202. doi: 10. 1002/ cncy. 20029.

\section{How to cite this article?}

Srivastava M.K, Srivastava K, Baig M.Q, Asharam, Vahikar S. Comparative evaluation of Bethesda system with conventional reporting method in assessment of thyroid malignancy rate. Trop J Path Micro 2018;4(8):597-603.doi: 10.17511/jopm.2018.i08.09. 